\title{
LA CONSTITUCIÓN EUROPEA Y LOS NUEVOS ESTADOS MIEMBROS DE LA UNIÓN EUROPEA
}

\author{
RUBÉN DARÍO TORRES KUMBRIAN \\ Facultad de Humanidades de la UCLM \\ Subdirector de La Musa, Revista de Pensamiento, \\ Universidad y Red, consagrada a temas europeos
}

SUMARIO

1. La ampliación de la Unión fue la clave principal de las sucesivas reformas de los Tratados y del nacimiento de la constitución Europea.

1.1. La Declaración 23: una pasarela al proceso constituyente.

1.2.. La Declaración de Laeken y el nacimiento de una convención.

1.2.1. La participación restringida impuesta a los Estados Candidatos en la Convención.

1.3. La Constitución y la Ampliación según los constructores de opinión de los Quince y de los Diez.

1.4. El proceso de ratificación de la Constitución Europea en los Diez nuevos Estados miembros de la Unión.

\section{LA AMPLIACIÓN DE LA UNIÓN FUE LA CLAVE PRINCIPAL DE LAS SUCESIVAS REFORMAS DE LOS TRATADOS Y DEL NACIMIENTO DE LA CONSTITUCIÓN EUROPEA}

El derribo del muro de Berlín significó el inicio de la cuenta regresiva para la reunificación del viejo continente bajo el manto de la libertad, y el Tratado de Maastricht dio a luz a una Unión Europea con mayor solidez constitucional. Sin embargo, la necesidad de una reforma institucional que permita la gobernabilidad de una Unión Europea ampliada, que puede alcanzar a más de treinta Estados miembros en los próximos años, fue la prin- 
Con arreglo a las conclusiones de los Consejos Europeos de Helsinki y de Niza, la Unión Europea debía estar en condiciones de acoger a partir de finales del años 2002 a los nuevos Estados miembros que estén preparados. El Tratado de Niza culminó la etapa del modelo institucional comunitario, que nació en el Consejo Europeo de Maastricht, y dio paso al proceso constituyente que condujo al Proyecto de Tratado Constitucional.

Cuando la CIG cerró el acuerdo sobre el Tratado de Niza el 11 de diciembre del año 2000, se ignoraba cuándo y en qué orden se produciría la adhesión de los entonces países candidatos a la Unión. El Tratado estableció para una Unión compuesta de quince Estados miembros el nuevo reparto de escaños en el Parlamento Europeo, la nueva composición de la Comisión y la nueva definición de la mayoría cualificada en el Consejo. El Tratado se limitó a establecer los principios y los métodos de evolución de ese sistema a medida que la Unión Europea se fuera ampliando. Estos principios y métodos se hallan recogidos en el Protocolo sobre la Ampliación y en las declaraciones anexas, en particular la Declaración relativa a la ampliación, en la se establece la posición común de los Quince que debían adoptar en las negociaciones con los países candidatos. ${ }^{5}$

Por ejemplo, el número de escaños que les correspondían en el Parlamento Europeo, el número de votos que se les atribuían en el Consejo y, en particular, el umbral de la mayoría cualificada aplicable en el futuro, debían determinarse jurídicamente en los tratados de adhesión. ${ }^{6}$

En el Protocolo sobre la ampliación y en las declaraciones correspondientes únicamente se tuvieron en cuenta los doce Estados candidatos con los que las negociaciones de adhesión se habían iniciado.

Las modificaciones introducidas por el Tratado de Niza en lo que respecta a la composición de la Comisión y la ponderación de votos sólo serían aplicables a partir del año 2005, y la nueva composición del Parlamento Europeo se aplicaría a partir de las elecciones del 13 de junio de 2004. Por consiguiente, en lo que respecta los entonces países candidatos cuya adhesión se produjo el 1 de mayo de 2004, en los tratados correspondientes de adhesión se determinaron asimismo el número de diputados europeos, de comisarios, de votos en el Consejo, así como el umbral de la mayoría cualificada, hasta la entrada en vigor de las nuevas normas. Esas disposiciones temporales debían determinarse con arreglo a los principios que rigieron las negociaciones de adhesión, a saber, la transposición del sistema respetando una igualdad de trato con los Estados miembros de dimensiones comparables. ${ }^{7}$

En relación al proceso de toma de decisiones, el Tratado de Niza amplió en alguna medida el ámbito de la toma de decisiones por mayoría cualificada. Una lista de veintisiete disposiciones que pasaron íntegramente o en parte, de la unanimidad a la mayoría cualificada. ${ }^{8}$

Con el Tratado de Niza finalizó la fase de la profundización en el modelo de la Unión mediante reformas de mínimos y se inició otra, la del proceso constituyente, de reforma de

1 Tratado de la Unión Europea. Editado con el patrocinio del Banco Exterior de España-Argentaria. DL: M-33077-1992. Pág. 334.

2 Tratado de Ámsterdam. Edita: Civitas Ediciones SL. ISBN: 84-470-1036-8. DL: M. 32.563-1999. Pág. 154.

3 Tratado de Ámsterdam. Edita: Civitas Ediciones SL. ISBN: 84-470-1036-8. DL: M. 32.563-1999. Págs. 222-223. 
cipal motivación de la reformas sucesivas de los Tratados y del nacimiento de la Constitución Europea.

El Tratado de Ámsterdam firmado el dos de octubre de 1997, supuso la revisión fallida del Tratado de la Unión Europea firmado en Maastricht el 7 de febrero 1992, que previó en su artículo N.2 que «en 1996 se convocará una Conferencia de los representantes de los Gobiernos de los Estados miembros para que examine, de conformidad con los artículos A y B de la disposiciones comunes, las disposiciones del presente Tratado para las que se prevea una modificación». ${ }^{1}$

La razón de esta revisión radicó en que las sucesivas ampliaciones supusieron una paulatina inviabilidad de un sistema concebido para seis Estados miembros, un hecho que se agravaría con las futuras adhesiones debido a la multiplicación de intereses nacionales en juego. La necesaria reforma institucional inconclusa generó el riesgo de colapsar una estructura que nació para garantizar el funcionamiento de seis Estados miembros y que estaba destinada a acoger a más de veinte en los próximos años.

Por este motivo, el Tratado de Ámsterdam incorporó el Protocolo sobre las Instituciones en la Perspectiva de la Unión Europea que en su artículo 2 precisó que «Al menos un año antes de que el número de Estados miembros de la Unión Europea exceda de Veinte, se convocará una conferencia de representantes de los gobiernos de los Estados miembros con el fin de efectuar una revisión global de las disposiciones de los Tratados sobre la composición y funcionamiento de las instituciones» ${ }^{2}$

Ámsterdam reconociendo su fracaso, anunció nuevas Conferencias Intergubernamentales, con el propósito de abordar la inconclusa reforma institucional. Las modificaciones del Tratado no permitieron realizar la reformas internas necesarias para que la Unión Europea pudiese afrontar la mayor ampliación de su historia.

El Tratado de Ámsterdam puso en evidencia la tibieza política de los líderes que integraban el Consejo, una tibieza que contrastaba con el empuje de sus antecesores, los protagonistas de la gran galopada europea en Maastricht y Edimburgo. La reforma de Ámsterdam no abordó la reforma institucional pero incorporó el nuevo Título VI bis que bajo, la rúbrica de Disposiciones sobre una Cooperación Reforzada, contenían los principios generales para una mayor integración de naturaleza sectorial entre los Estados que así lo deseasen en el terreno comunitario y en materia penal. (3)

La Conferencia Intergubernamental (CIG) concluyó sus trabajos el día 11 de diciembre del año 2000, en Niza, con un acuerdo sobre las cuestiones institucionales que no se resolvieron en Ámsterdam y que debían resolverse antes de la ampliación, así como sobre otras cuestiones no relacionadas directamente con la ampliación. Posteriormente, el acuerdo fue objeto de revisión jurídico-lingüística para que el Tratado fuera firmado en Niza el 26 de febrero del año 2001. ${ }^{4}$

4 SEC (2001) 99 Comisión de la Comunidades Europeas. Secretario General. Nota a a la atención de los Miembros de la Comisión. Síntesis del Tratado de Niza. Bruselas, 8 de enero del año 2001. Pág. 1.

5 Tratado de Niza. Protocolo sobre la Ampliación de la UE y Declaración n ${ }^{\circ} 23$ relativa al futuro de la Unión. Edita: Civitas Ediciones SL. ISBN: 84-470-1578-5. DL: M. 16.751-2001. Págs. 61 y 95.

6 SEC (2001) 99 Comisión de la Comunidades Europeas. Secretario General. Nota a a la atención de los Miembros de la Comisión. Síntesis del Tratado de Niza. Bruselas, 8 de enero del año 2001. Pág. 2. 
El punto 3 de la Declaración afirmó expresamente que en el año 2001, la Presidencias sueca y belga, en colaboración con la Comisión y con la participación del Parlamento Europeo, debían favorecer un amplio debate con representantes de los Parlamentos nacionales y del conjunto de la opinión pública tales, como los círculos políticos, económicos y universitarios, los representantes de la sociedad civil. Finalmente el punto 3 señaló que a este proceso debían sumarse los Estados candidatos en una modalidades de participación pendientes por definir.

El 11 de diciembre del año 2000, el Presidente de la República de Francia, Jacques Chirac comenzaba su balance personal del fin de la presidencia francesa en estos términos: «Esta cumbre de Niza quedará en la historia como una gran cumbre, por la amplitud y complejidad de los problemas que ha dejado resueltos». ${ }^{11}$

Semanas más tardes, el 26 de febrero de 2001, el presidente Chirac hizo un balance histórico del Tratado de Niza ante el Parlamento Europeo, lanzando una invitación entusiasta a su ratificación y a su entrada en vigor rápida, en los siguientes términos: «El Tratado de Niza es un tratado coherente y equilibrado, que todos debemos firmar. Como acuerdo europeo es fruto de un compromiso que no responde, por supuesto, a las ambiciones de algunos. Pero se trata del mejor tratado posible, que permitirá a la Europa de mañana funcionar con eficacia». ${ }^{12}$

El presidente, Chirac continuó ante el Parlamento Europeo, el Consejo y la Comisión, afirmando: «Corresponde a todos los Estados proceder a la ratificación de este tratado. En lo que concierne a Francia iniciaremos rápidamente el proceso de ratificación. Debemos considerar que en Niza se firmó el Tratado de la ampliación y en consecuencia, debemos cumplir nuestro contrato.»

Esta investigación no tiene por objeto la realización de un análisis en profundidad de la evolución constitucional de la Unión, ni tampoco pretende introducir una perspectiva comparativa de las ventajas y desventajas que contienen tanto Niza como el Proyecto de Tratado Constitucional presentado por la Convención. Sin embargo, no pasa inadvertida la existencia de un desencuentro profundo entre el espíritu teórico de la Declaración 23, y el desarrollo del proceso político constituyente, un desencuentro que probablemente sea una de las causas de un humus nuevo de desconfianza y desilusión reinante en una parte de las sociedades de los Diez nuevos Estados miembros de la Unión.

Teniendo en cuenta aspectos concretos de la Declaración 23 como por ejemplo la delimitación precisa del debate propuesto, la mención expresa de Niza como el Tratado que preparó institucionalmente a la Unión para la ampliación, la pretensión de un debate

7 SEC (2001) 99 Comisión de la Comunidades Europeas. Secretario General. Nota a a la atención de los Miembros de la Comisión. Síntesis del Tratado de Niza. Bruselas, 8 de enero del año 2001. Pág. 2 (párrafo $3^{\circ}$ ).

8 SEC (2001) 99 Comisión de la Comunidades Europeas. Secretario General. Nota a a la atención de los Miembros de la Comisión. Síntesis del Tratado de Niza. Anexo lista de Disposiciones. Bruselas, 8 de enero del año 2001. Págs. 15 y 16.

9 Tratado de Niza. Declaración no 23 relativa al futuro de la Unión. Edita: Civitas Ediciones SL. ISBN: 84-470-1578-5. DL: M. 16.751-2001. Pág. 100.

10 Resolución del PE sobre el Tratado de Niza y el futuro de la Unión, 31 de mayo del año 2001. /A-50168/ 2001. En http//www.ueroparl.eu.int. 
los fundamentos políticos y jurídicos del sistema a través de un debate global y nuclear, sobre las relaciones de poder en que se apoya, afectando a la misma raíz de la construcción europea. La Conferencia Intergubernamental adoptó en Niza la Declaración 23 sobre el futuro de la Unión, mediante la cual se solicitó un debate más amplio y profundo sobre el desarrollo de la Unión Europea. En el año 2001, las presidencias sueca y belga, en colaboración con la Comisión, debían favorecer un amplio debate con todas las partes interesadas, incluyendo al proceso a los Estados entonces candidatos. El Consejo Europeo de Laeken de diciembre de 2001 adoptó una Declaración en la que se debían indicar las iniciativas adecuadas para la continuación del proceso en curso. ${ }^{9}$

\subsection{LA DECLARACión 23: UNA PASARELA AL PROCESO CONSTITUYENTE}

El Tratado de Niza otorgó a la Unión Europea una salida constitucional transitoria que posibilitó la ampliación, al tiempo que inició el proceso constituyente con la Declaración 23 relativa al futuro de la Unión. El Tratado de Niza puede ser caracterizado como una pasarela directa al proceso constituyente protagonizado por la Convención y la Conferencia Intergubernamental. La misma Declaración 23 fue considerada por el Parlamento Europeo como un reconocimiento implícito por parte de los Jefes de Estado y de Gobierno del agotamiento del método diplomático de revisión de los Tratados para adoptar las reformas que necesita la Unión ${ }^{10}$

Los puntos 2 y 8 de la Declaración 23 son especialmente destacables porque pueden sugerir que cuestiones institucionales de peso no serían objeto de reforma. El primero de ellos señaló que la CIG abrió paso a la ampliación de la Unión Europea, al tiempo que subrayó que con la ratificación del Tratado de Niza, la Unión Europea habría completado los cambios institucionales necesarios para la adhesión de nuevos Estados miembros. El punto 8 de la Declaración invitaba a participar en la Conferencia a aquellos Estados candidatos que hubieran concluido las negociaciones de adhesión con la Unión y en calidad de observadores a aquellos candidatos que no las hubieran concluido.

La Declaración 23 anunció el inicio de un debate en profundidad sobre el futuro de la Unión que se tradujo en la Conferencia Intergubernamental, al tiempo que determinó el objeto de la discusión en su punto 5. La distribución de competencias entre la Unión y los Estados miembros conforme al principio de subsidiariedad, el estatuto de la Carta de derechos fundamentales de la Unión Europea proclamada en Niza en diciembre de 2000, la simplificación de los Tratados y el papel de los Parlamentos nacionales en la arquitectura institucional de la Unión.

La sustancia política de la Declaración permitió emprender un proceso constituyente que dotó a esta etapa de la construcción europea de un método único e inédito, el de un debate abierto a la sociedad civil, donde la democracia, legitimidad y transparencia pretendieron ser la columna vertebral.

11 ABC. Quiñonero, Juan Pedro. ¿ Qué vale la palabra de Chirac ?. 14 de diciembre del año 2003. Pág. 38.

12 Declaración de Laeken, Conclusiones de la Presidencia, Consejo Europeo de Laeken. 14 y 15 de diciembre de 2001. http://ue.eu.int. 
labor.

La Declaración estableció un contenido amplio sobre el que se basó el trabajo del debate estructurado, recogió expresamente el análisis de las conclusiones del debate público, y consideró específicamente los puntos de la Declaración 23, a los que añadió el estudio de una reforma institucional en profundidad. El Consejo Europeo, a través de la Declaración de Laeken, inició formalmente el debate relativo a este proceso de reformas con la convocatoria de una Convención que presidió. Giscard d'Estaing.

La Convención Europea, reunió a representantes de todas las legitimidades europeas, que a través del debate estructurado generaron consensos y disensos derivados del debate entre las tendencias federalistas e intergubernamentalistas. El método de Convención funcionó debido a que permitió un debate democrático, abierto, en contacto con la sociedad civil y fue capaz de obtener unos resultados sin precedentes en la historia del constitucionalismo supranacional.

La Declaración de Laeken recordó cuál es la realidad de la Unión, diseñó el contenido material de la reforma por medio de unas sesenta y cinco preguntas y estableció el procedimiento que debía seguir la Convención. El método de Convención fue un método de rasgos federales, debido a que estableció un considerable equilibrio entre las distintas legitimidades presentes en la construcción europea.

Durante el año 2001 se produjo la insistencia generalizada por parte del Parlamento europeo y de los sectores europeístas en que se volviera a aplicar el método de la Convención, que tan buenos resultados había dado en la redacción de la Carta de Derechos de la Unión Europea. (13)

Con el método de Convención se inició la superación del método diplomático de reforma, debido a que se encargó la preparación de una Conferencia Intergubernamental a un órgano democrático de concepción representativa. El órgano democrático contó con la doble legitimidad, nacional y europea, propia de la Unión Europea.

La Declaración de Laeken reguló la composición de la Convención, con un total nominal de 105 miembros, a los que se añadieron los suplentes, pero esa regulación tuvo que ser radicalmente modificada en sentido expansivo. Laeken aglutinó las dos legitimidades presentes en la construcción europea, la nacional y la de las instituciones comunes.

Por parte de las instituciones comunes, la Convención Europea incluyó a dieciséis representantes del Parlamento Europeo y a dos de la Comisión. Los Estados miembros y candidatos, enviaron a dos representantes del Parlamento nacional y uno del Jefe de Estado o de Gobierno. Junto al Presidente y Vicepresidentes se contempló un Presidium de nueve miembros destinado a la dirección de los trabajos de la Convención, donde estuvieron representadas las Presidencias del Consejo de la Unión Europea, los Parlamentos nacionales, el Parlamento Europeo y la Comisión.

La Declaración Laeken además reservó el papel de observadores a representantes del Comité Económico y Social, el Comité de las Regiones y al Defensor del Pueblo. Otra de las novedades de este método de construcción constitucional fue la participación del Foro de la Sociedad Civil en los trabajos de la Convención, a través de la información regular de los trabajos de la Convención y su contribución a los debates. La iniciativa supuso un reconocimiento a la importancia de la sociedad civil en la vida política, lo que unido a las contribuciones en abierto de los ciudadanos a través de Internet, puede considerarse como un mecanismo novedoso de democracia participativa en el debate.

En definitiva, se puede afirmar sin temor a exagerar que la Convención y su método 
democrático, legítimo y transparente, y las modalidades de participación de los entonces Estados candidatos, se puede comprender el punto de vista de los estudiantes y de los profesores polacos y de otros centroeuropeos cuando en algunas ocasiones me preguntaron: Nuestro pueblo aprobó el referéndum de la Adhesión según las condiciones de Niza», o «la Declaración 23 no abrió un debate con el propósito de cambiar el peso político de cada país en el Consejo».

Personalmente, debo puntualizar que carezco de los atributos necesarios para la práctica política, y por tanto, para ofrecer una respuesta aparentemente convincente a esta cuestión. Por otro lado, desde un punto de vista académico, tengo una abundante cantidad de preguntas, un océano de dudas y ninguna respuesta concluyente. Seguramente, la combinación de mi europeísmo desarraigado nacionalmente con mi subjetiva y nada científica tendencia de ponerme en línea con los considerados más vulnerables me impiden encontrar una respuesta objetiva. Desde la óptica de mis convicciones personales, mi preferencia por los métodos de trabajo de la Convención y por una Constitución de tendencia federal es indudable, pero a pesar de ello no dejo de hacerme las siguientes preguntas:

¿Qué puede pasar con el futuro de la Unión si la ausencia de columna vertebral del discurso del presidente Chirac se convierte en el estilo político dominante del resto de los miembros del Consejo Europeo?

Sí una estructura institucional concebida para seis Estados miembros no es viable para la Europa de los Veinticinco, ¿ puede el eje franco-alemán persistir en un estilo liderazgo que fue óptimo para la Europa de los Seis y de los Doce, pero que para la UE-25 puede ser interpretado como una pretensión de hegemonía neodespótica e ilustrada ?

Al margen de esta reflexión personal orientada a la solicitud de respuestas posibles y volviendo al tema que venía desarrollando, debo afirmar que la Declaración 23 dio un impulso decisivo a un proceso constituyente único en el mundo que se emprendió definitivamente con la Declaración de Laeken, un paso político de gigantes que supuso la primera concreción audaz del nuevo debate.

La Declaración de Laeken, por medio de un lenguaje innovador, examinó los desafíos que debía superar la Unión Europea y los modos de acometerlos, lo que se planteó a través de unas sesenta y cinco preguntas. La Declaración de Laeken encargó la preparación de los trabajos de la Conferencia Integubernamental a una Convención similar a la que redactó la Carta de Derechos Fundamentales de la Unión Europea.

\subsection{La DeClaración de Laeken y el nacimiento de una Convención}

La Declaración fue adoptada por el Consejo Europeo de Laeken, celebrado los días 14 y 15 de diciembre del año 2001, supuso la apertura de una etapa de la preparación de la reforma prevista por la Declaración 23 aneja al Tratado de Niza y diseñó una fase del proceso constituyente caracterizada por un debate estructurado.

La Declaración de Laeken puso en movimiento una implícita interpretación federalista moderada de la Declaración 23 del Tratado de Niza. A través de un lenguaje innovador formuló unas sesenta y cinco preguntas dirigidas al análisis de los desafíos que debía superar una Unión Europea en vía de expansión, y los viables modos de acometer con éxito la 
acometer esta reforma después de la ampliación con el objeto de garantizar una igualdad absoluta de participación efectiva en el proceso constituyente?

Sin embargo, hay que destacar la explosión del espíritu democrático de la Convención con la adopción de normas sobre sus métodos de trabajo que derivó en considerables modificaciones al diseño inicial de la misma por la Declaración de Laeken.

Las peticiones y contribuciones de los convencionales, especialmente de los representantes del Parlamento Europeo fueron un combustible decisivo a este impulso democrático. Los Estados candidatos obtuvieron la posibilidad de contar con un representante en el Presidium en calidad de miembro invitado y se clarificó la cuestión de los suplentes, lo que modificó de hecho la composición de la Convención, que contó efectivamente con unos 230 miembros.

La Declaración de Laeken contuvo una limitación importante al señalar que los miembros de la Convención sólo podían ser sustituidos por los suplentes en caso de ausencia. Sin embargo, la Convención superó este límite y permitió la participación de los suplentes, incluso en el uso de la palabra y su inclusión en los grupos de trabajo, en condiciones prácticamente iguales a las de los titulares.

Resulta fundamental poner en relieve que los convencionales fueron, generalmente, políticos de primer nivel en sus países o en la escena política europea. El Presidente de la Convención fue Valery Giscard D’estaing y los Vicepresidentes, Giuliano Amato y Jean Luc Dehane. Los restantes miembros del Presidium fueron Michael Barnier, Representante de la Comisión Europea; John Bruton, Representante de los Parlamentos Nacionales; Henning Christophersen, Representante de la Presidencia Danesa; Alfonso Dastis, Representante de la Presidencia Española, a partir de marzo de 2003;

Kalus Hänscha, Representante del Parlamento Europeo; Giorgio Katiforis, Representante de la Presidencia Griega, hasta febrero de 2003; Iñigo Méndez de Vigo, Representante del Parlamento Europeo; Ana Palacio, Representante de la Presidencia Española, hasta marzo de 2003; Giorgio Papandreu, Representante de la Presidencia Griega, a partir de febrero de 2003; Gisela Stuart, Representante de los Parlamentos Nacionales; Antonio Vittorino, Reperesentante de la Comisión Europea y Alojz Peterle, invitado. De la lectura de estos nombres se desprende una ausencia notable en el Presidium de representantes de los diez nuevos Estados miembros de la Unión.

Considerando lo anterior debo recordar que los países candidatos tuvieron tres representantes cada uno en la Convención, uno en representación del gobierno y dos en representación del parlamento nacional, aunque la participación de los mismos quedó reducida al uso de la palabra, sin posibilidad de impedir el consenso.

No puedo dejar de resaltar que algunos miembros de la Convención y durante el transcurso de la misma han aportado reflexiones valiosas a dos obras que he tenido el privilegio de dirigir. El libro Polonia y España ente el futuro de la UE, presentado en la salón de actos del edificio de la Comisión Europea en Madrid, dos días después de la Cumbre de Bruselas.

La segunda obra fue, La Ampliación Europea y otras claves de la Construcción Europea (Lamusa n ${ }^{\circ}$ ), presentada en la Facultad de Humanidades el 29 de abril del año

13 Resolución del Parlamento Europeo sobre el Tratado de Niza, de 31 de mayo del año 2001 
de trabajo fueron pioneros y vanguardia en la ingeniería constitucionalista supranacional, y probablemente la futura Constitución Europea será colocada por la historia en el mismo olimpo donde brillan los grandes hitos constitucionales de la humanidad. En este sentido, se puede afirmar que el gran logro histórico de la Convención desde una perspectiva filosófica fue el de materializar una síntesis entre el espíritu de las leyes de Montesquieu y la voluntad general de Jean Jacques Rousseau.

Llegado a este punto surgen una serie interrogantes de carácter sociológico y politológico de gran calado :

¿Qué grado de representatividad social generan estas nuevas formas de democracia participativa?

¿El mecanismo de democracia participativa logró generar un entusiasmo por la ampliación europea en el ciudadano medio y disipar sus temores?

¿Sí hay una apuesta sincera por los mecanismos de democracia participativa, porqué se limitó la capacidad de participación de los representantes de los Estados candidatos?

¿Cómo se garantiza una fiable designación de los agentes sociales?

No hay duda que con sólo estos cuatro interrogantes podría llevar a cabo un prolijo trabajo de investigación durante la próxima década.

El mandato que recibió la Convención en la Declaración de Lacken fue estudiar las distintas cuestiones planteadas y llegar a un documento final que pudiese comprender bien diferentes opciones, precisando el apoyo que hubieren recibido, bien recomendaciones en caso de consenso. En todo caso, la Conferencia Intergubernamental es la que tiene la última voz y adoptará la decisión final. Por tanto, el mandato teórico de la Convención consistió sólo en actuar como grupo de reflexión en la preparación de la Conferencia Intergubernamental.

Teniendo en cuenta lo anterior, se debe destacar que el mandato teórico fue superado en la realidad debido a que la Convención redactó y adoptó con un nivel considerable de consenso una propuesta de Tratado constitucional. La diferencia entre la unanimidad y el consenso es vital cuando lo que está en juego es la elaboración de un nuevo marco político de convivencia política, económica y social, y por ello, no podemos pasar por alto que el gran desencuentro en la Convención y en la posterior la Cumbre del Consejo Europeo de Bruselas de diciembre del año 2003, se produjo entorno al reparto de poder, sobre todo en el aspecto de poder lograr minorías de bloqueo.

\subsubsection{La participación restringida impuesta a los Estados Candidatos en la Convención}

La Convención incardinó su trabajo en una dinámica de participación restringida de los representantes de los Estados candidatos, una representación igualitaria en número a la de la representación de los Estados miembros, pero devaluada en cuanto a la igualdad de trato político o de capacidad de acción. El déficit democrático en el método de participación de los Estados candidatos radicó a que no podían impedir el consenso. Teniendo en cuenta esta limitación, una pregunta surge irremediablemente:

¿La imperativa igualdad de trato político en la Europa de los Veinticinco no aconsejaba 
Hubner, ${ }^{14}$

Los gobiernos nacionales fueron y son los principales encargados de explicar los procesos de ampliación y constituyente a los ciudadanos de los Quince y de los países candidatos. La Comisión apoyó esa labor y preparó una estrategia de comunicación para explicar la ampliación europea. Todos los agentes responsables de que llegase a buen término ambos procesos debieron transmitir con claridad el mensaje de que con la ampliación y la Constitución, la totalidad de Europa y sus ciudadanos son los beneficiados debido a que la Unión de los Veinticinco constituye una zona de paz, prosperidad y seguridad con influencia en el resto del continente.

Los Quince y los Diez intentaron, con escaso éxito, aumentar la concienciación y el conocimiento sobre los procesos de ampliación y constituyente. Ambos procesos debieron ser explicados, difundidos y publicitados con mayor intensidad propagandística positiva acerca de los beneficios resultantes de una Unión Europea de los Veinticinco.

Los mensajes relativos estabilidad política, a la perspectiva de conseguir un crecimiento económico sostenible duradero, a los enormes avances que se lograron en las reformas económicas y políticas llevadas a cabo por los Diez desde 1989, a la conveniencia de una Constitución Europea como domador normativo de la globalización, quedaron considerablemente eclipsados por una corriente de opinión, de diverso origen, construida sobre los aspectos más controvertidos, y muchas veces infundados, exagerados o imaginados de ambos procesos. Por estos motivos resulta adecuado incluir el presente epígrafe referente a las diversas visiones que los constructores de las opiniones públicas de la Europa de los Veinticinco tuvieron de los procesos constituyente y de ampliación.

Los miembros del Consejo y los constructores de opinión europeístas en general, deben abandonar el paradigma shumpeteriano de la comunicación política y asumir que la opinión pública es una fuerza incontrolable, como afirmó el Primer Ministro británico Canning en el siglo XIX. La hipnosis mediática de la masas es ajena a la naturaleza de nuestro sistema político, pero en caso de llevarse a cabo, jamás pueden predeterminarse las consecuencias. Las consecuencias de un juego de este tipo siempre beneficiará a las concepciones antieuropeas.

En cuanto a los constructores de opinión pública, he clasificado a los mismos utilizando la tipología, modificada levemente, del sociólogo francés Marcel Merlé, que clasifica la opinión pública en las relaciones internacionales en: opinión oficial, opinión militante, opinión especializada y opinión general. (15)

Aunque utilice la tipología clasificatoria sociológica de Merlé, las siguientes líneas realizadas bajo la saludable tiranía de la pluralidad, no pretenden ser un análisis sociológico o politológico de los contenidos, por el contrario tienen la vocación de ser un sintético testimonio notarial-periodístico que permita al lector obtener una breve panorámica informativa de uno de los momentos históricos más emblemáticos de la Unión Europea.

Valery Giscard D’estaing, Presidente de la Convención: «Esta evolución no pretende dar lugar a una interpretación errónea, como la de que la Convención pretende ser una Conferencia intergubernamental disfrazada, en las que los gobiernos negociarán fuera de la Convención. La Convención, es un recinto democrático. Es en ella donde se desarrolla el debate con toda transparencia. Son los participantes los que deberán buscar mucha moderación, humildad ante la historia e independencia con respecto a las ideas recibidas y a las presiones institucionales, la búsqueda del consenso sobre la mejor Constitución para 
2004, por el entonces embajador de la República Checa, Martín Povjsil; la Consejera de Asuntos Europeos de la Embajada de Polonia, Joanna Grodzka; la Consejera de Asuntos Europeos de la Embajada de Eslovaquia, Luba Hromkova ; la Consejera de Asuntos Europeos de la Embajada de Hungría, Angela Klimes de Gosztonyi; la Consejera de Asuntos Europeos de la Embajada de la República Checa, Pavla Harlíková y el Director de los Encuentros Españoles de Estudios de Europa Oriental de la Universidad de Valencia, Carlos Flores Juberías.

Las obras en cuestión aglutinaron trabajos brillantes de los siguientes Convencionales: del Representante del Parlamento Europeo, Carlos Carnero; Joseph Borrel Fontelles, Representante del Parlamento de España; del miembro del Presidium; Alfonso Dastis Quecedo; de la Representante del Gobierno de Polonia, Danuta Hübner; del Representante del Parlamento de Polonia, Jozef Oleksy; del Representante del Parlamento de Eslovaquia, Jan Figel; del Representante del Gobierno de la República Checa, Jan Kohout; del Representante del Parlamento Checo, Josef Zieleniec.

Siguiendo con el tema de la presente exposición, hay que señalar que el Presidente Giscard agrupó a los convencionales en tres grupos diferente. La corriente bruselense conformada por los representantes de las instituciones comunes, Parlamento y Comisión aportaron un profundo conocimiento del sistema y, en gran medida, se centraron en la reforma institucional.

Los representantes de los Parlamentos nacionales fueron mayoría, procedentes de una amplia diversidad partidista que dificultó su integración en los métodos de trabajo de la Convención. Por último, el grupo de los representantes de los Gobiernos garantizó la vinculación entre la Convención y Estados miembros, lo cual otorgó mayores cuotas de realismo y posibilismo políticos.

La labor de la Convención se dividió en tres fases bien diferenciadas. La primera fase fue de audiencias y permitió establecer los asuntos que la Convención debía examinar, a través de los debates entre los miembros de la Convención y de la audiencia a la sociedad civil y a la Convención de los jóvenes. El desarrollo de esas sesiones plenarias posibilitaron consensos y generaron una aproximación a los asuntos objeto de estudio.

Los Grupos de Trabajo desarrollaron su labor de estudio a lo largo de la segunda fase. También se realizó una serie de consultas estructuradas con el Foro de la Sociedad Civil y se decidió la constitución de ocho grupos de contacto que celebraron reuniones con representantes de la Convención periódicamente.

El Proyecto de Tratado por el que se instituye una Constitución para Europa, en la versión entregada al Presidente del Consejo Europeo en Roma el 18 de julio del año 2003 y adoptado por la Convención el 13 de junio y el 10 de julio del año 2003, se puede considerar una síntesis transaccional entre las aportaciones de las tradicionales corrientes federal e intergubernamental de la construcción europea.

\section{3.-LA CONSTITUCiÓn y LA Ampliación SEgÚN LOS CONSTRUCTORES DE OPINIÓN DE LOS QUINCE Y DE LOS DIEZ}

„Hay que tratar de que en la discusión sobre la nueva forma de la Unión no haya vencedores ni vencidos. En la nueva casa europea debe haber sitio para todos y hay que dejar los aposentos para los próximos moradores que quieren tomar residencia y aceptar los principios que rigen esta casa.» Danuta 
de la Dieta en la Convención: «El presente año 2003 ha sido dedicado a la elaboración del texto del Tratado, sobre las bases establecidas en los informes finales de los grupos de trabajo y las conclusiones de los debates plenarios. El proyecto del Tratado de Constitución ha sido dividido en tres partes: la parte constitucional, las políticas concretas y las normas generales y finales. De esta forma ordenada la Nueva Constitución Europea va a abarcar los contenidos de los tratados actuales, complementados con nuevos elementos establecidos por la Convención.

En los trabajos de la Convención de la Unión Europea se nota claramente un interesante proceso de creación de la vida política interna y de las formas exteriores que influyen en la misma. Por un lado se marcaron las dicotomías entre los representantes de los gobiernos y de los parlamentos, entre las familias políticas europeas y entre los países grandes y pequeños. Por el otro, los países miembros de la Unión Europea ejercían sus influencias formales e informales, presentando a través de sus delegados contribuciones reglamentarias, refiriéndose de forma vinculante a los trabajos de la Convención durante conferencias bilaterales y multilaterales o concensuando posiciones en los foros del Consejo Europeo. También fue un rasgo específico de la Convención la importancia, creciente a medida del progreso de sus trabajos, de su Presidium, con Valery Giscard d'Estaing como Presidente, al frente». ${ }^{20}$

Alfred Grosser : «Para que la ampliación no colleve una especie de disolución de la Unión, que se convertiría en un simple conjunto comercial y monetario, hay que transformar las instituciones. Ahí es donde se esperaba la acción impulsora del motor franco-alemán. Y es ahí donde está el fallo». ${ }^{21}$

Josep Borrell Fontelles, Representante del Parlamento español en la Convención: «Con el proceso constituyente y con la ampliación, el proyecto europeo se enfrenta a un triple problema de dimensión, legitimidad y eficacia; de territorio, de democracia y de poder. La Convención nació del semi fracaso de Niza y de la conciencia de que se hacía necesario superar el método intergubernamental para dar un nuevo impulso al proyecto europeo».22

Gustavo de Arístegui, Diputado por Guipúzcoa, Portavoz del PP en la Comisión de Asuntos Exteriores y Diplomático: «Estamos viviendo un período especialmente importante tanto para la Unión Europea y los países que vamos a ingresar en breve, como para todo el mundo. La aprobación del Tratado de Adhesión, su firma en Atenas el 16 de abril de 2003 y luego su ratificación tanto por los actuales como por los futuros países miembros, permitirán cumplir la fecha establecida de la ampliación, el día 1 de mayo de 2004.

Al mismo tiempo, la Convención presentó el proyecto del Nuevo Tratado de la Unión Europea que será aprobado en la próxima Conferencia Intergubernamental. El fortalecimiento de la política exterior de la UE y de su papel en el mundo están entre las mayores

14 Hubner Danuta, Secretaria de Estado del Ministerio de Asuntos Exteriores de Polonia y Representante del Gobierno en la Convención. Lamusa n 2: La Ampliación Europea y otras claves de la Construcción Europea. La Constitución Europea y el Futuro de Europa: el punto de vista polaco Edita: Facultad de Humanidades de la UCLM, 2004, Pág. 98.

15 Merle Marcel. Sociología de las Relaciones Internacionales. Las Fuerzas Transnacionales, La Opinión Pública Internacional Edita: Alianza Editorial (C. Sociales- Alianza Universidad), Madrid, 1995, Pág. 451. 
Europa» ${ }^{16}$

Jan Kohout Secretario de Estado y Primer Viceministro de Asuntos Exteriores y Representante del Gobierno de la República Checa en la Convención: «A la Convención, que deriva su legitimidad de las decisiones de los Consejos Europeos realizados en Niza y Laeken, se le propuso la tarea de hacer una arquitectura europea más simple, eficiente y ante todo, acercarla de nuevo a los ciudadanos de la Unión.

Después de un comienzo confuso, en el que los participantes de la Convención y la Convención misma, se buscaban un poco a sí mismos, y ante todo el objetivo, el producto final, que debería alcanzarse, siguieron las negociaciones después del verano con un ritmo increíble. Diez grupos de trabajos investigando los aspectos individuales de la actividad de la UE y proponiendo cambios según el espíritu de dichos mandatos, aceleraron notablemente la actividad de la Convención. Un cambio crucial fue el momento, en el que resultó evidente que la Convención iba a preparar para la siguiente conferencia intergubernamental nada menos que el borrador de la Constitución de la Unión Europea. La discusión se desarrolló plenamente, sobre las propuestas a los parámetros de la futura configuración de la Unión, tanto dentro como, con frecuencia, fuera de la misma por las actuaciones de algunos políticos europeos prominentes»». ${ }^{17}$

Luis Ortega Álvarez, Catedrático de Derecho Administrativo, Catedrático Jean Monnet de Derecho Comunitario y Director del Centro de Estudios Europeos de la UCLM: «(....) Hasta ahora la identidad de las Instituciones Europeas ha estado basada en en la identidad política de los Estados miembros. Nosotros, como europeos, hemos unificado muchas políticas públicas, pero la base real de la política con mayúsculas todavía se encuentra localizada dentro de las fronteras de los Estados miembros. Si pretendemos hablar seriamente de una Constitución Europea, debemos aceptar que estamos proponiendo nuevos instrumentos de legitimación de las Instituciones europeas basados en una relación directa entre la Unión y sus ciudadanos y no entre aquella y los ciudadanos de los Estados miembros. Sin embargo el dotarnos de un nuevo concepto político de Europeos como un pueblo único y unificado supone, sin duda, subir un escalón muy crucial en nuestra historia que no todos están dispuestos a dar. El actual borrador de Constitución elaborado por la Convención para el futuro de Europa, ha abandonado, precisamente, la expresión del pueblo europeo como el sujeto impulsor de la reforma, y se ha recogido en cambio como sujetos del impulso del nuevo Tratado a los ciudadanos y a los Estados, ciudadanos, que como sabemos, lo son, no en cuanto europeos, sino en cuanto ciudadanos de dichos Estados. A mi juicio, la futura, así denominada, Constitución Europea no deja de tener la misma naturaleza que los anteriores Tratados comunitarios.» ${ }^{18}$

Carlos Carnero, Representante del Parlamento Europeo en la Convención.»La Convención Europea se convocó para deliberar, pero ha sobrepasado su misión convirtiéndose en constituyente, asumiendo una posición situada entre la reforma y la ruptura.» ${ }^{19}$ Józef Oleksy, Presidente de la Comisión Europea de la Dieta Polaca y Representante

16 Destaing, Valery Giscard, Presidente de la Convención. EL PAÍS. La Convención Sobre El Futuro De Europa En Su Ecuador. 14 de enero del año 2003. Pág. 4.

17 Kohout, Jan, Secretario de Estado y Primer Vice-Ministro de Asuntos Exteriores de la República Checa y Representante del Gobierno en la Convención. Lamusa n 2: La Ampliación Europea y otras claves de la Construcción Europea. Comentarios sobre la Convención por parte del representante del gobierno checo. Edita: Facultad de Humanidades de la UCLM, 2004, Pág. 65. 
la UE tenga como objetivo la seguridad en el plano internacional que orientar la seguridad de los ciudadanos en el marco de un mundo más justo, con menos pobreza y más respeto a los derechos de todos los ciudadanos. $\rangle^{27}$

Danuta Hubner: Secretaria de Estado del Ministerio de Asuntos Exteriores de la República de Polonia: «(...) la Convención Europea, al comienzo quizá un poco desestimada, ha ganando un rango y ha sabido convencer a los europeos de su valor. Los países miembros han mostrado mucha perspicacia al invitar a los países candidatos a esta ronda que debatirá las visiones de la futura Europa común. Los miembros de la Convención provenientes de Europa y de otros países que participan activamente en sus trabajos y esperan que su contribución se traduzca en soluciones concretas. Ya en este momento se podría dibujar el bosquejo del futuro Tratado Constitucional. (...) Considero que la Convención ya ha logrado mucho el consenso de preparar un Tratado Constitucional único que reemplazará a los Tratados actualmente vigentes, enormemente extensos y bastante nebulosos. Esta simplificación contribuirá mucho a acercar a la Unión a los ciudadanos, sobre todo si tenemos en cuenta que no hace mucho tiempo parecía poco real aplicar la palabra constitución en un trabajo internacional referente a la Unión Europea. (...) Para nosotros, los polacos, el punto de partida de la discusión sobre el futuro de la Europa unida es la constatación de que las adaptaciones y reformas indispensables en la arquitectura institucional de la Unión no pueden de ninguna manera poner en tela de juicio los mecanismos y principios que constituyen el fundamento del proceso de integración. Consideramos que estos cambios han de tener carácter pragmático y servir sobre todo a los ciudadanos y a la verificación de los principios fundamentales de la Unión. Las reformas propuestas deben afianzar el equilibrio institucional en el marco de la Unión, deben garantizar la igualdad de todos lo países miembros y han de contribuir a afianzar el papel de la Unión Europea en el mundo. (....) El futuro Tratado definirá los principios de funcionamiento de la Unión Europea para los próximos decenios. Independientemente de las opiniones que prevalezcan, sea de los países grandes o de los pequeños, se trata mecanismos más gubernamentales o más unitarios, de opiniones más cercanas a delegados de gobiernos o parlamentarios, hay que tratar de que en la discusión sobre la nueva forma de la Unión no haya vencedores ni vencidos. En la nueva casa europea debe haber sitio para todos y hay que dejar los aposentos para los próximos moradores que quieren tomar residencia y aceptar los principios que rigen esta casa.» ${ }^{28}$

Jozef Zieleniec, Representante en la Convención por el Parlamento de la República Checa: «El Presidente de la UE debería tener algunas competencias simbólicas y protocolares dentro de los asuntos internos de la Unión, pero en ningún modo. Cercenando las competencias de otras instituciones o alterando el método comunitario y sin que impida a cualquier país miembro involucrarse regularmente en la organización de los asuntos de la

18 Ortega Alvarez, Luis, Director del Centro de Estudios Europeos de la UCLM. Polonia y España ante el Futuro de la Unión Europea. La Prospectiva de una Constitución Europea. Patrocinan y Colaboran: Facultad de Humanidades de la UCLM, Ministerio de Asuntos Exteriores de Polonia y Embajada de Polonia en España, Centros de Estudios Europeos de la UCLM y de Varsovia, etc.. Edita: Librería Popular. ISBN: 8493278971. Págs. $137-143$.

19 Carnero, Carlos, Eurodiputado Socialista y Representante del PE en la Convención. Lamusa n ${ }^{\circ}$ : La Ampliación Europea y otras claves de la Construcción Europea. Europa necesita una Constitución: apuntes para un desafío. Edita: Facultad de Humanidades de la UCLM, 2004, Págs. 149-154 . 
prioridades de la Convención y de la Conferencia Intergubernamental». ${ }^{23}$

Alain Touraine, Director del Instituto de Estudios Superiores de París: «Se trata de reconocer que Europa, precisamente ahora que se amplía y cuando, por consiguiente, se vuelven más difíciles los problemas de su cohesión interna, desaparece cada vez más completamente de la escena mundial. Es imposible no interrogarse sobre la razón de ser y el futuro de Europa, Durante mucho tiempo ,algunos países, y en especial Francia, han visto en Europa la creación de un nuevo Estado nacional, y algunos pensadores sobre todo lo s alemanes, se entusiasmaron con la formación de una conciencia europea que les protegiera de los peligros de la conciencia nacionalista de su propio país. Todas estas concepciones claras y ambiciosas hoy se han abandonado claramente. Europa parece una zona de gestión de problemas de baja intensidad.... ${ }^{24}$

Ján Fígel, Presidente de la Comisión de Relaciones Exteriores del Parlamento de Eslovaquia, Representante del Parlamento en la Convención y Negociador Principal para la Adhesión de Eslovaquia a la UE: «La exitosa conclusión de las negociaciones de acceso colocó en primer plano un nuevo reto tanto para los países miembros de la UE, como para los países candidatos. El resultado de la Convención sobre el futuro de Europa - cuyo tema es el futuro de la Europa ampliada - y la posterior conferencia intergubernamental, coadyuvarán a establecer las perspectivas del futuro del proyecto de integración. La ampliación representa una oportunidad única de avanzar en todos los aspectos positivos de las antiguas experiencias de la integración europea y de desempolvar y mejorar aquellos ámbitos que han de ser reformados. La ampliación replanteará el mapa geográfico, histórico, económico y político de la Unión Europea. Si debe conservarse y seguir desarrollándose el sistema actual de cooperación y de creación de una política común, las instituciones y las políticas de la Unión Europea tendrán que cambiar». ${ }^{25}$

Klaus Hänsch, Miembro de la Mesa de la Convención: «Para avanzar en la construcción europea es necesario un mayor grado de transparencia y de asunción democrática de responsabilidades en la toma de decisiones. (....) El modelo europeo debe basarse en el desarrollo sostenible, el pleno empleo, la innovación y la cohesión social» ${ }^{26}$

Giuliano Amato, Vicepresidente la Convención Europea : «Los fines y los valores que inspiren la Constitución Europea tienen mucha importancia, porque influirán de forma directa en las opciones políticas y jurídicas de la Unión Europea. (....) No es lo mismo que

20 Oleksy, Józef. Presidente de la Comisión Europea de la Dieta Polaca y Representante de la Dieta en la Convención. Polonia y España ante el Futuro de la Unión Europea. La visión polaca de la futura Europa en el contexto de los trabajos de la Convención. Patrocinan y Colaboran: Facultad de Humanidades de la UCLM, Ministerio de Asuntos Exteriores de Polonia y Embajada de Polonia en España, Centros de Estudios Europeos de la UCLM y de Varsovia, etc.. Edita: Librería Popular. ISBN: 8493278971. Págs. 115-120.

21 Grosser, Alfred, Profesor Emérito de C. Políticas en París y Presidente del Centro de Información e Investigación sobre Alemania.. 19 de enero del año 2003. Pág. 12.

22 Josep Borrell Fontelles, Representante del Parlamento español en la Convención. Temas Para el Debate. La Constitución Europea. LA Constitución Europea y el gobierno económico de Europa. Enero de 2003. № 98. Pág. 22.

23 Gustavo de Arístegui, Diputado por Guipúzcoa, Portavoz del PP en la Comisión de Asuntos Exteriores y Diplomático. Polonia y España ante el Futuro de la Unión Europea. El Reto Europeo de Polonia. Patrocinan y Colaboran: Facultad de Humanidades de la UCLM, Ministerio de Asuntos Exteriores de Polonia y Embajada de Polonia en España, Centros de Estudios Europeos de la UCLM y de Varsovia, etc.. Edita: Librería Popular. ISBN: 8493278971. Págs. 179-186. 
quea la Carta Magna. Alemania y Francia culpan a España y Polonia y amenazan con formar un núcleo duro. El primer ministro italiano y presidente de turno de la Unión Europea, Silvio Brlusconi, admitió sin embargo que a lo largo de las negociaciones España y Polonia se mostraron abiertas para llegar a un acuerdo. Una opinión compartida por el primer ministro británico, Tony Blair.» ${ }^{33}$

José Antonio Zarzalejos, Director de ABC: «Ni Francia ni Alemania disponen ya de capacidad de persuasión ni de presión para sobreponer sus intereses al conjunto de la UE. El Consejo de ayer ha sentenciado el final del liderazgo franco-alemán y acreditado la inconsistencia de Berlusconi y su extravagante forma de conducirse en los asuntos internacionales. Si la Constitución de la UE se hubiese aprobado conforme a las pautas urdidas por uno de los políticos más desacreditados y nacionalistas de toda Europa-Valery Giscard D'estaing habría triunfado un nuevo Richelieu.» ${ }^{34}$

Juan Carlos González, Periodista de El Mundo: «España y Polonia piden al eje franco alemán que no les pase factura en los presupuestos por el fracaso de la Cumbre. El debate presupuestario debe separarse del constitucional, dijo Leszek Millen ${ }^{35}$

Francois Hollande, Secretario General del Partido Socialista Francés: «La manera con que Schöder y Chirac abordaron la Cumbre de Bruselas no podía favorecer la unión. Francia y Alemania han deseado demostrar que bastaba con ponerse de acuerdo entre dos, para poner de acuerdo a veinticinco....pues bien, esa manera de actuar ya no funciona. Chirac y Schöder prepararon mal y se comportaron pero antes, durante y después de la Cumbre europea de Bruselas, son el pero ejemplo de comportamientos europeos, ambos se ha comportado con mucha ligereza. Primero, violaron y dinamitaron el Pacto de Estabilidad. Incumplida la disciplina común, Chirac y Schöder quieren que todo el mundo acepte como buenas, sin discutir, las exigencias de Francia y Alemania. Esas no son maneras de comportarse. España y Polonia sólo son responsables en parte del fracaso y también puede decirse lo mismo de Berlusconi..» ${ }^{36}$

Rosa Díez, Eurodiputada: (La Eurocámara arremete contra los que reclaman un recorte de fondos. Los seis países contribuyentes netos piden que el techo presupuestario sea reducido al 1 por ciento del PIBc. La carta fue enviada a la Comisión Europea y firmada por Francia, Alemania, Austria, Suecia, Holanda y el Reino Unido y llegó dos días después de la Cumbre de Bruselas, lo que reforzó la sensación de que se trata de un castigo inflingido en primer lugar). «la carta puede ser considerada como una amenaza contra los países de la cohesión. No aceptamos que España sea castigada por un fracaso que es colectivo sobre la Constitución. La iniciativa de los seis, además envía una señal muy negativa a

24 Touraine, Alain, Sociólogo y Director del Instituto de Estudios Superiores de París. EL PAÍS. ¿Existe Europa?. 20 de enero del año 2003. Pág. 12.

25 Ján Fígel, Presidente de la Comisión de Relaciones Exteriores del Parlamento de Eslovaquia, Representante del Parlamento en la Convención y Negociador Principal para la Adhesión de Eslovaquia a la UE.Lamusa $n^{\circ}$ 2: La Ampliación Europea y otras claves de la Construcción Europea. Eslovaquia y la arquitectura de la UE después de la ampliación. Edita: Facultad de Humanidades de la UCLM, 2004, Págs. 96-99 .

26 Hänsch, Klaus, Parlamentario europeo (PSE/SPD), ex Presidente del Parlamento Europeo y miembro de la mesa de la Convención. Temas Para el Debate. La Constitución Europea. Más Europa para más gente. Enero de 2003. Nº 98. Pág. 30.

27 Amato, Giuliano, Vicepresidente de la Convención Europea. Temas Para el Debate. La Constitución Europea. La Convención Europea. Enero de 2003. No 98. Pág. 19. 
Unión.

(...) Este amargo debate sobre el posible presidente de la Unión entre los países más grandes y más pequeños, representantes de los gobiernos y de la Comisión, etc., nos ha llevado a olvidar el positivo potencial de que la existencia de un Presidente de la UE podría tener en términos de visibilidad y familiaridad de la UE para sus ciudadanos, también para los representantes y ciudadanos de terceros países. Sería una pena si la Convención ignorase ese potencial. El debate en blanco y negro, a favor y en contra del Presidente de la UE, debería pararse y ser sustituido por la búsqueda de una solución cualitativa siendo capaz de trascender las divergencias existentes. El Presidente de la UE no es necesariamente una buena o una mala solución, depende de cómo y con qué fin se cree ese cargo.»» ${ }^{29}$

Carlos Yárnoz, Periodista de El País: «El Presidium de la Convención sobre el futuro de Europa difundió ayer su proyecto final de Constitución Europea que ahora será debatido en pleno antes de presentarlo a los líderes el 20 de junio en Salónica. El texto incluye rebajas impuestas por Londres en política Exterior y defensa frente al deseo franco-alemán. Se ha impuesto la tesis británica de que la decisiones en ese terreno se adopten, como norma general, por unanimidad, como ahora, y no por mayoría cualificada. Las diferencias más arduas subsisten en el capítulo institucional, que ha quedado pendiente. En cuanto a las decisiones el texto indica que se tomará por una mayoría de Estados que represente al menos al 60 por cineto de la población de la UE. La fórmula beneficia a los países grandes, echa por tierra las arduas y complejas negociaciones del Tratado de Niza y subleva a Estados medio-grandes como España y Polonia». ${ }^{30}$

Enrique Serbeto, Periodista de ABC: «Cuando los observadores ya presagiaban que Giscard estaba llevando al secretario de Estado español (Alfonso Dastis Quecedo) directamente a la cámara de las torturas, para obligarle a mostrarse como causa del bloqueo, apareció en el hemiciclo una providencial declaración firmada por ocho países que no están en el Presidium, pero que respaldan las tesis españolas de que el Tratado de Niza no se debe tocar: $<<$ no es perfecto, lo sabemos, pero representa un punto de equilibrio entre los distintos intereses que están en juego y, a pesar de las críticas fáciles de algunos, consideramos que puede rendir un buen servicio a la Unión (la Declaración fue firmada por Gran Bretaña, Polonia, Suecia, Dinamarca, Irlanda, Austria, Lituania y Chipre) ${ }^{31}$

Juan Carlos González y Carlos Segovia, Periodistas de El Mundo: «Aznar ve posible un acuerdo en Bruselas par salvar la nueva Constitución Europea. Alemania y Reino Unido se muestran proclives a elevar al sesenta y seis por ciento el umbral de la población. No representa para España llegar al poder de Niza, pero las altas fuentes del Gobierno consultadas señalaron que podría ser aceptable. Pero este gesto debería ir acompañado de más compensaciones. Entre ellas, elevar la presencia española en el Parlamento Europeo. Aznar quiere diez diputados más para España a agregar a los cincuenta que tendrá la Unión de veintisiete países». ${ }^{32}$

Juan Carlos González, Periodista de El Mundo: «La UE no logra aprobar su Constitución. LA guerra por el reparto de poder hace fracasar la Cumbre de Bruselas y blo-

28 Hubner Danuta, Secretaria de Estado del Ministerio de Asuntos Exteriores de Polonia y Representante del Gobierno en la Convención. Lamusa n 2: La Ampliación Europea y otras claves de la Construcción Europea. La Constitución Europea y el Futuro de Europa: el punto de vista polaco Edita: Facultad de Humanidades de la UCLM, 2004, Pág. 95-98. 
tampoco pudo resolver la cuestión, y por tanto, no pudo adoptar la Constitución Europea.

Desde el 1 de mayo del años 2004, cuando se celebró la fiesta de la ampliación con los líderes de la Europa Veinticinco, Berthie Ahern presidente del Consejo de la UE continuó desplegando un titánico y discreto esfuerzo para despejar los desacuerdos relativos al reparto del poder y conseguir la Constitución Europea. Los obstáculos radicaron, principalmente, en la fijación de unos porcentajes al sistema de doble mayoría que permitan generar mayorías y también minorías de bloqueo.

Los días 17 y 18 de mayo en Bruselas, los ministros de Exteriores de los Veinticinco cerraron el proyecto constitucional, excepto en los aspectos políticamente más sensibles como el reparto de poder, los límites al veto o las referencias a la religión. Sin embargo, la gran cita decisiva sería la Cumbre Europea de Bruselas de junio del año 2004 destinada a cerrar los temas más sensibles y a designar al nuevo presidente de la Comisión.

El Primer Ministro irlandés Bertie Ahern, realizó una gira de sondeo por las capitales europeas con una propuesta del sistema de doble mayoría que establecía el cincuenta y cinco por ciento de los Estados y un sesenta y cinco por ciento de la población.

La opinión pública dominante sostuvo que el cambio de gobierno en España facilitó el acuerdo, debido a la aceptación del sistema de doble mayoría. Sin embargo, una parte significativa de la opinión circulante en el ámbito diplomático sostenía que el anterior gobierno español estaba dispuesto a aceptar el sistema de doble mayoría tras el fracaso colectivo de la Cumbre de Bruselas de diciembre de 2003.

Polonia, también experimentó un cambio de gobierno por la dimisión del Primer Ministro Lezcek Miller y de todo su equipo el 2 de mayo de 2004. el Presidente de la República de Polonia, Aleksander Kawsniewski, anunció una posición negociadora más abierta para posibilitar el acuerdo, entre sus propuestas se puede destacar la aceptación del sistema de doble mayoría con una variación porcentual que quedaba en el cincuenta y cinco por ciento de Estados que representen al menos al sesenta y cinco por ciento de la población.

Parte de la prensa española trató de identificar la firme postura negociadora de Polonia con una posición antieuropea, una difamación carente de todo fundamento. Para entender la posición polaca sólo debemos recordar la posición negociadora española inmediatamente anterior a 1986. El 17 de febrero de 1985, el actual Presidente del Congreso Español, Manuel Marín, siendo Secretario de Estado para las Relaciones con la Comunidad Europea, declaró: «España no está dispuesta a romper la baraja, pero tampoco aceptará entrar en la Comunidad firmando un tratado que pueda crear una situación de inferioridad insuperable en el futuro.» ${ }^{44}$

La reflexión de Marín se adaptaba a las negociaciones de la Constitución Europea, debido a que una Carta Magna que comporte la formación de hegemonías nacionales

29 Zieleniec, Józef, Senador y Representante del Parlamento de República Checa en la Convención. Lamusa $n^{\circ}$ 2: La Ampliación Europea y otras claves de la Construcción Europea. La Cuestión de la Presidencia en la Unión Europea: Presidencia de la UE, Presidencia del Consejo Europeo, Presidencia del Consejo. Edita: Facultad de Humanidades de la UCLM, 2004, Pág. 69-74.

30 Yárnoz, Carlos. EL PAÍS. 27 de mayo del año 2003. Pág. 3.

31 Serbeto, Enrique. ABC. 31 de mayo del año 2003. Pág. 32.

32 González, Juan Carlos y Segovia, Carlos. El Mundo. 12 de diciembre del año 2003. Pág. 25. 
los diez nuevos socios que entrarán el próximo 1 de mayo en la Unión y que registran rentas inferiores a la media de la $\mathrm{UE})^{37}$

Ricardo M De Rittuerto, Periodista de El País : «El Parlamento Europeo expresó ayer en duros términos su decepción por la incapacidad de la CIG de sacar adelante una nueva Constitución para Europa. Las palabras fracaso, pesar, decepción, amargura, atronaron los oídos de Silvio Berlusconi, que había ido a la eurocámara a presentar los resultados de la fallida Cumbre de Bruselas. $)^{38}$

Romano Prodi, Presidente de la Comisión Europea: «Aunque la mayoría de los Eurodiputados rechaza la Europa de las dos velocidades, puede ser el necesario catalizador de una reacción que saque a Europa del atolladero. Unanimidad (Parlamento Europeo) hubo en la negativa a mezclar el debae constitucional y el reparto de poder en la UE con las perspectivas financieras, a la luz de los recortes de fondos planteado por seis países. Los Europarlamentarios consideran imcompati8ble ese plan con la Unión que se quiere construir.» ${ }^{39}$

Oliver Duhamel : «Si es España y Polonia son culpables de que no se adoptara la Constitución, Francia y Alemania son responsables.» ${ }^{40}$

Le Figaro: «Tras la Cumbre, Francia no ha resistido la tentación de dar todavía algunas lecciones. Un poco menos de arrogancia no perjudicaría a nuestra diplomacia. En Francia tenemos que barrer mucho delante de nuestra puerta». ${ }^{41}$

Daniel Vernet (Le Monde) : «Quizá los grandes estados, sospechosos de querer imponer su voluntad, estarían más a sus anchas para pedir respeto a las reglas comunes si nos las pisotearan cuando les conviene». ${ }^{42}$

Bertie Ahern, Presidente del Consejo Europeo (cadena pública británica BBC): «Confío en que tendremos una Constitución, pero todavía hay algunos temas fundamentales que tenemos que resolver y puede llevar algún tiempo» ${ }^{43}$

\subsection{El proceso de RATificación de la Constitución Europea en los DiEZ NuEvos EsTAdos MIEMBROS DE LA UNIÓN}

La Secretaría de la Convención, puso en conocimiento de los miembros de la Convención, el texto definitivo del proyecto de tratado por el que se instituye una Constitución para Europa, en la versión entregada al Presidente del Consejo Europeo en Roma, el 18 de julio de 2003. El citado proyecto de tratado fue adoptado por consenso por la Convención Europea el 13 de junio y el 10 de julio de 2003. Sin embargo, es necesario recordar que el tan predicado consenso pudo lograrse debido a que la Convención cerró la cuestión del reparto de poder en falso, con la expresa oposición de los representantes gubernamentales de Polonia y de España. El principal foco de discrepancia se trasladó a la Conferencia Intergubernamental que en la Cumbre de Bruselas de diciembre del año 2003,

33 González, Juan Carlos. El Mundo. 14 de diciembre del año 2003. Pág. 22.

34 Zarzalejos, José Antonio, Director de ABC. ABC. El fin del liderazgo franco-alemán. 14 de diciembre del años 2003. Pág. 5

35 González, Juan Carlos. El Mundo. 15 de diciembre del año 2003. Pág. 27. 2003.

36 Hollande, Francois, Secretario General del Partido Socialista de Francia. ABC. 16 de diciembre del años 
te de dos años. La entrada en vigor del Tratado Constitucional implica la necesidad de que el proceso de ratificación se realice por unanimidad. En este sentido, el artículo IV-447 referente a la ratificación y entrada en vigor establece:

1. El presente Tratado será ratificado por las Altas Partes Contratantes, de conformidad con sus respectivas normas constitucionales. Los instrumentos de ratificación serán depositados ante el Gobierno de la República Italiana.

2. El presente Tratado entrará en vigor el 1 de noviembre de 2006, siempre que se hayan depositado todos los instrumentos de ratificación o, en su defecto, el primer día del segundo mes siguiente al del depósito del instrumento de ratificación del último Estado signatario que cumpla dicha conformidad.

Sin embargo, la Constitución en su artículo IV-443.4 relativo al Procedimiento de revisión ordinaria otorga la posibilidad de que si cuatro quintas partes de los países la aprueban, es decir veinte países, el Consejo Europeo tomará conocimiento de la cuestión y decidirá. De este modo, los padres de la Constitución Europea, diseñaron un texto que da la facultad discrecional al Consejo para que decida en cada caso, cabiendo así la posibilidad de otorgar la oportunidad al país en cuestión de repetir el proceso de ratificación, de crear un estatuto especial o de abandonar la Unión Europea (Artículo I-60, Retirada voluntaria de la Unión)

Artículo.IV-443.4. Si, Transcurrido un plazo de dos años desde la firma del Tratado por el que se modifica el presente Tratado, las cuartas quintas partes de los Estados miembros lo han ratificado y uno o varios Estados miembros han encontrado dificultades para proceder a dicha ratificación, el Consejo examinará la cuestión.

Una interpretación no extensiva de los Artículos IV-447, IV-443.4 y I-60, descartan las visiones trágicas o dramáticas sobre las dificultades del proceso de ratificación o sobre el mito de la creación de un Estado Federal Europeo sin posibilidad de salida voluntaria.

La interpretación politológica del conjunto de los preceptos anteriores no puede ser otra que:

A) la práctica política que dio la oportunidad a Dinamarca y a Irlanda de repetir la ratificación de los Tratados de Maastricht y de Niza, respectivamente queda constitucionalizada a través del Artículo IV-443.4.

B) las soberanías nacionales ejercidas de modo efectivo y real desde 1989 en los Estados miembros del centro y este de la Unión, quedan garantizadas con la posibilidad de salida voluntaria conforme al Artículo I-60.

C) el riesgo real de que el Reino Unido rechace la Constitución, queda reducido con

38 Ricardo M De Rittuerto, Ricardo M De. El PAÍS. 17 de diciembre del año 2003. Pág. 8

39 Prodi, Romano, Presidente de la Comisión Europea. ELPAÍS. 17 de diciembre del año 2003. Pág. 8

40 Duhamel, Oliver. EL MUNDO. 19 de diciembre del año 2003. Pág.23.

41 LE FIGARO. EL MUNDO. 19 de diciembre del año 2003. Pág. 23.

42 Vernet, Daniel. LE MONDE. EL MUNDO. 19 de diciembre del año 2003. Pág. 63.

43 Ahern, Bertie. Presidente del Consejo Europeo. Cadena pública británica BBC. 1 de enero del año 2004. 
minoritarias, puede atentar contra un anhelo generalizado de los ciudadanos europeos, que no es otro que el de dotarnos de una Constitución que posibilite la Cohesión y la igualdad de trato político.

Cualquier pretensión en sentido contrario, puede hacer creíble la malvada profecía que la ex Primer Ministra británica, Margaret Tatcher, pronunció el 5 de noviembre de 1995 cuando declaró: «Tenemos una Europa alemana. Muchos de los miembros de la Unión Europea hacen lo que Alemania quiere porque es el mayor contribuyente». ${ }^{45}$

No era previsible un sometimiento español y polaco, a las exigencias francesas y alemanas en las negociaciones sobre el reparto del poder en la Constitución. España es un Estado miembro con fama de duro negociador y Polonia lleva una línea similar desde las negociaciones de adhesión.

La posición expresada por el Ministro de Exteriores y de Cooperación, Miguel Ángel Moratinos, indicaba la anterior posibilidad cuando afirmó que «En la Constitución Europea, no aceptamos que un directorio de países pueda ignorar la legitimidad de dos tercios de la población europea.(.). No nos vamos a someter a un vasallaje de Francia y

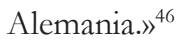

Se hacía imprescindible el pensamiento de uno de los mayores europeístas de nuestro tiempo: Jaques Delors. El 1 de enero del año 1989, cuando renovó su mandato al frente de la Comisión, manifestó que «si no abrimos una ventana para que los ciudadanos puedan palpar la Comunidad, no lograremos interesarles. Uno no se enamora del gran mercado. Por eso hay que dar un alma a la Comunidad». ${ }^{47}$

El nacimiento de una Europa de los Veinticinco en vías de expansión hacia una Unión de más treinta Estados miembros necesitaba una alma. El alma era una Constitución Europea que posibilite la construcción de la Cohesión, Económica, Social, Territorial y también Política.

Del proyecto de Tratado de Constitución Europea se desprende que la Convención fue eficaz en la hora de elaborar propuestas dirigidas a estructurar la vida política y el espacio político europeo en la Europa de los Veinticinco, Veintisiete o más y en hacer que la Unión se convierta en un factor decisivo de la estabilidad y en un modelo supranacional de domesticación de la globalización.

El Prefacio del proyecto de tratado de Constitución Europea predica que la Carta Magna contempla un nítido reparto de las competencias de la Unión y de los Estados miembros, establece una fusión de los Tratados y atribuye a la Unión de personalidad jurídica, determina una simplificación de los instrumentos de actuación de la Unión; propone medidas para aumentar la democracia, la transparencia y la eficacia de la Unión Europea impulsando la aportación de los parlamentos nacionales a la legitimidad del proyecto europeo, simplificando el procedimiento decisorio y haciendo más transparente y comprensible el funcionamiento de las instituciones europea y presenta las medidas necesarias para mejorar la estructura y reforzar el papel de cada una de las tres instituciones de la Unión teniendo en cuenta, particularmente, las consecuencias de la ampliación.

El 18 de junio de 2004, los Jefes de Estado y de Gobierno de la UE de los Veinticinco adoptaron el Tratado por el que se establece una Constitución para Europa. El texto constitucional fue firmado en Roma el 29 de octubre de 2004, dando lugar al inicio de un proceso de ratificaciones nacionales por vía parlamentaria o referéndum con el plazo lími- 
La Ley sobre Acuerdos Internacionales de 14 de Abril de 2000, no determina una fecha límite para la ratificación de un acuerdo internacional. Sin embargo, debemos recordar que el Proyecto de Tratado Constitucional firmado en Roma el 29 de octubre de 2004, inició un proceso de ratificaciones nacionales por vía parlamentaria o referéndum con el plazo límite de dos años. Hasta el momento no existe ningún indicio o dificultad de tipo político que haga plausible la hipótesis de que el proceso de ratificación polaco se extienda más allá del plazo de dos años.

A los analistas occidentales y centroeuropeos que auguran obstáculos insalvables en el proceso de ratificación polaco, basándose en el bajo nivel de participación de la ciudadanía en las elecciones del Parlamento Europeo y en otros factores de política doméstica. Habría que recordar que en contra de muchas previsiones la mayor parte de la sociedad polaca apoyó decididamente la adhesión de Polonia a la Unión Europea, en un contexto político y sociológico de apasionados debates, reflexiones, cuestionamientos sobre determinados costes de la integración y apoyos sin reservas a la causa europea. Los resultados de ese referéndum fueron de un 77,45 \% por el sí y un 22, $55 \%$ por el no.

En Polonia el debate sobre el procedimiento de ratificación del Tratado Constitucional todavía no ha culminado, por tanto, no se sabe cuando el Parlamento adoptará la decisión sobre el procedimiento de ratificación que se empleará.

En el inicio del debate sobre la vía de ratificación, las fuerzas políticas mayoritarias se inclinaron por el rechazo al referéndum. En septiembre de 2003, la Cámara Baja polaca (Sejm) rechazó una moción que apoyaba la vía del referéndum. La Alianza Democrática de Izquierdas (SLD) y la Plataforma Cívica (PO) se opusieron al referéndum. Las fuerzas políticas que apoyaron la vía del referéndum fueron Justicia y Ley (PIS) y la Liga de las Familias Polacas (LRP), que expresaron un rechazo al proyecto de Tratado Constitucional de la Unión Europea.

Hacia finales de 2004, el devenir de los acontecimientos políticos polacos parecen indicar que podría existir la posibilidad de emplearse la vía del referéndum en la segunda mitad del año 2005, coincidiendo con las elecciones presidenciales. Otra opción barajada coincide con las elecciones regionales de otoño de 2006. Los defensores de estas fechas sostienen que así se garantizaría el nivel de participación necesaria para la realización de un referéndum.

La vía parlamentaria para la ratificación implica la aprobación por parte del Sejm (Cámara Baja) y de la Cámara Alta (Senado). En relación a la vía parlamentaria de ratificación se debe destacar que el Artículo 90, en su párrafo cuarto, de la Constitución de Polonia, establece que el Sejm, a través de la mayoría absoluta de votos y en presencia de al menos la mitad de los diputados, aprueba la Ley sobre el procedimiento de ratificación.

44 Marín, Manuel. Secretario de Estado para las Relaciones con la Comunidad Europea (17 de febrero de 1985). EL PAÍS SEMANAL 20 años no 1203, domingo 29 de mayo de 1996. Pág. 127.

45 Tatcher, Margaret. Ex Primer Ministra británica (5 de noviembre de 1995). EL PAÍS SEMANAL 20 años $n^{\circ} 1203$, domingo 29 de mayo de 1996. Pág. 129.

46 Moratinos, Miguel Ángel. Ministro de Asuntos Exteriores y de Cooperación de España. ABC. Entrevista realizada por Luis Ayllón. 10 de mayo del año 2004. Págs. 12 y 13.

47 Delors, Jacques. Presidente de la Comisión Europea (1 de enero de 1989). EL PAÍS SEMANAL 20 años $n^{\circ} 1203$, domingo 29 de mayo de 1996. Pág. 127. 
la posibilidad que otorga el artículo 443.3 de poder diseñar un estatuto específico que permitiese a este Estado su permanencia en el Mercado Interior y otros sectores de la Unión.

D) la diversidad de concepciones europeístas y los grados de pertenencia a la Unión vigentes y cambiantes en los Estados miembros son asumidos por la Constitución Europea.

E) la compatibilidad de las Veinticinco naturalezas estatocéntricas y sus respectivas culturas políticas y trayectorias históricas, con la vocación supranacional de la Unión Europea queda exclusivamente garantizada por la libertad de decisión, permanencia y grado de pertenencia de las partes contratantes.

F) las visiones fatalistas referentes al proceso de ratificación de la Constitución Europea, por las vías parlamentaria o del referéndum son insostenibles al amparo del Artículo IV- 443.4. Teniendo en cuenta lo anterior, la aparición de obstáculos a la ratificación en alguno de los Veinticinco Estados miembros podrán ser superados por la capacidad discrecional a nivel político que el artículo 443.4 brinda al Consejo Europeo.

G) Teniendo en cuenta lo descrito en el punto F, se debe interpretar que la vocación de preferencia por la ratificación unánime expresada por el Artículo IV-447, es perfectamente compatible con el reconocimiento del riesgo de no poder concretarla, y por tanto, la necesidad de brindar soluciones alternativas, tal como establece el Artículo 443.4 o I-60.

\subsubsection{Polonia}

Polonia es el país que ha tenido el privilegio de infligir la primera grieta irreparable del Muro de Berlín a partir de los finales de la década del setenta, no hay duda que el Papa Juan Pablo II y el movimiento Solidaridad, fueron los catalizadores que encauzaron los vitales anhelos de libertad, democracia y de pertenencia al proceso de construcción de la Unión Europea.

Polonia es el país territorialmente más grande y más poblado del centro del continente europeo. Su extensión es de 312.685 kilómetros cuadrados y su población asciende a 38.218.500 habitantes. La tasa de paro se eleva al 19,2 \% y su posición en el Índice de Desarrollo Humano (PDHM-ONU), que mide el bienes y el progreso de un país en función de indicadores como la educación, la esperanza de vida, etc, se encuentra en el puesto 35.

La base jurídica que regula los procedimientos del proceso de ratificación de la Carta Magna Europea en el caso de la República de Polonia, está constituida por los Artículos 89, 90 y 125 de la Constitución, por la Ley sobre Acuerdos Internacionales de 14 de Abril de 2000 y por la Ley de Referéndum Nacional de 14 de Marzo de 2003.

Las etapas formales del proceso de ratificación son tres:

A) El Consejo de Ministros adopta una resolución sobre la firma del Tratado.

B) La aprobación por vía parlamentaria o por la vía referéndum.

C) El Presidente de la República firma el acto de ratificación. 
ley específica. Dados los plazos legislativos en curso es más que probable que la celebración del referéndum no va a ser posible antes del otoño del año 2006.

Cómo ya se puso de manifiesto durante el desarrollo de la Convención y de la CIG, tradicionalmente existen en la República Checa diferentes opiniones y puntos de vista sobre hasta dónde debería ir la integración europea en su profundidad y cuál debería ser la futura forma de la Unión Europea. Por este motivo, existe un debate amplio sobre si el Tratado constitucional, tal y cómo fue aprobado por el Consejo Europeo en junio de 2004, es el instrumento más adecuado para responder a todos los retos de una Unión Europea en vías de expansión y que determinará el futuro del país.

El principal partido político, el Partido Cívico Demócrata (ODS), es el principal partido que cuestiona aspectos importantes del Tratado Constitucional, y considera el debate legítimo y cívicamente necesario. Según sus representantes, la PESC o PESD representa un punto de análisis y de inquietud central, y se preguntan si de veras el Tratado Constitucional resuelve adecuadamente las necesidades de integración de la UE en este ámbito.

Los representantes del ODS consideran que en lo relativo a la PESC o PESD, existen gran diversidad visiones y ambiciones que no encuentran un reflejo adecuado en los pasos concretos para su materialización. La política exterior de la UE, según el ODS, está muy lejos de ser una política verdaderamente común y el Tratado constitucional en este sentido no resuelve este hueco entre la visión ambicionada y la realidad en curso.

Por los motivos, anteriormente mencionados las élites políticas de la oposición en la República Checa creen que hay que mantener un debate abierto y sincero sobre el futuro en la familia común de los estados europeos y que es inaceptable dividir la población en «chicos buenos» y «chicos malos» según si aceptan el Tratado constitucional o no, como según afirmó el Presidente Vaclac Klaus en su última visita oficial a España, durante una rueda de prensa ofrecida en el Palacio de la Moncloa, junto al Presidente español, José Luis Rodríguez Zapatero.

Václav Klaus: «Yo quiero decir que la Constitución Europea es para mí, y creo que debería de serlo para todo ciudadano europeo, un documento muy importante y que, por lo tanto, debería de celebrarse una discusión muy profunda al respecto. Yo me tengo resistir a este esquema, que a veces circula, por el cual el que está a favor de la Constitución Europea es una buena persona, es un «good guy», y el que están en contra es un «bad guy», una mala persona. Creo que, si esto fuera así, entonces sería caricatura de la democracia y una caricatura del diálogo en Europa. Por lo tanto, yo espero que todos juntos, junto con el Gobierno español, también en el futuro sigamos dialogando sobre este tema.»

pregunta: «Luego quería preguntarle por el tema de la Constitución Europea. Ha dicho usted «seguiremos dialogando sobre el tema». Pero la Constitución ya está aprobada y lo único que queda es la ratificación. ¿Entonces, quiere decir usted que van a reabrir el debate sobre la Constitución con idea de reformarla antes, incluso, de que sea ratificada o simplemente que van a recomendar que no se ratifique?»

Václav Klaus: «lógicamente, respeto que el texto de la Constitución Europea ya ha nacido, ya está en el mundo; que el 29 de octubre se firmará en Roma y en nombre de la República Checa lo firmará el Presidente del Gobierno y no el Presidente (Jefe de Estado). Es decir, yo creo que no hay ningún motivo para empezar ahora una nueva discusión a nivel de la Unión Europea y sobre la Constitución Europea; pero, en cambio, creo que el 
Si el Sejm adopta la vía parlamentaria de ratificación, el Artículo 90 de la Constitución, en su párrafo segundo determina que la Ley que aprueba la ratificación de un acuerdo internacional es aprobada por el Sejm a través de las dos terceras partes de votos afirmativos, en presencia de al menos la mitad de los diputados. El mismo precepto determina dos terceras partes de votos favorables la Cámara Alta, con la asistencia de al menos la mitad del número reglamentatio de Senadores.

En caso de que el Parlamento polaco adoptase la decisión de utilizar la vía de ratificación del referéndum, el Artículo 125 de la Constitución dice que el derecho de ordenar la realización del referéndum lo tiene el Sejm a través de la mayoría absoluta de votos favorables, en presencia de al menos la mitad del número reglamentario de diputados, o el Presidente de la República, con la previa aprobación del Senado, expresada por la mayoría absoluta de votos favorables, en presencia de al menos la mitad del número reglamentario de senadores.

También es destacable que el artículo 125 de la Constitución polaca establece que si en el referéndum nacional han participado más de la mitad de los ciudadanos con derecho a voto, entonces el referéndum es vinculante.

Finalmente el Jefe de Estado polaco formaliza el acto de ratificación del Proyecto de Tratado Constitucional de la Unión Europea, independientemente de la vía ratificación utilizada. $^{48}$

\subsubsection{República Checa}

El gobierno de la República Checa puso mucho énfasis en que el Tratado Constitucional de la Unión Europea sea aprobado sin sobresaltos. En la actualidad existe un consenso entre las principales fuerzas políticas checas acerca de que el instrumento más legítimo, o adecuado, para que la voluntad ciudadana pueda pronunciarse sobre el Tratado Constitucional, es la celebración de un referéndum.

Teniendo en cuenta lo anterior se debe destacar que la Constitución de la República Checa otorga a las dos cámaras del Parlamento la competencia de ratificar los tratados internacionales y el Tratado Constitucional de la Unión Europea es desde el punto de vista del derecho internacional, un tratado internacional. Por tanto, el referéndum checo va a ser solamente de carácter consultivo.

El desarrollo de la vida política en la República Checa sobre este asunto, me lleva a poder afirmar de modo categórico que no cabe ninguna duda, de que el resultado de la ratificación del Tratado Constitucional de la Unión Europea por el Parlamento checo va a ser afirmativo, consiguiendo la aprobación por mayoría de tres quintos en la dos Cámaras.

El propósito del gobierno checo es convocar el referéndum coincidiendo con las elecciones generales a la Cámara de los diputados, en el año 2006, a más tardar. La decisión final sobre la fecha de la celebración de la votación popular, sin embargo, está en manos del Jefe del Estado de Chequia, el presidente Václav Klaus, debido a que tiene la capacidad de firmar la fecha de celebración del referéndum.

En este momento, parece evidente, que por razones puramente legislativas, la República Checa no va a ser capaz de celebrar el referéndum en primavera del año 2005. La vía del referéndum no está prevista en la Constitución Checa, por tanto, hará falta una 
Europea. Los representantes políticos eslovacos siempre han insistido (antes de la adhesión) de que los representantes de nuevos Estados miembros de la UE podían participar, sin derecho a voto, en la Convención sobre futuro de Europa y posteriormente, en la Conferencia Intergubernamental poder votar sobre el texto del Tratado Constitucional.

El gobierno eslovaco sostiene, que el Tratado Constitucional simplifica la base jurídica de la Unión Europea y personifica la integración europea en una entidad: Unión Europea, que pasa a ser el sucesor universal de las anteriores tres comunidades. Hasta ahora había cuatro tratados constituyentes diferentes, de ellos el Tratado de la Unión Europea cubría las cuestiones del segundo-política exterior, y el tercer pilar — interior, justicia. La propuesta del Tratado Constitucional suprime la estructura de tres pilares y crea un sistema único de toma de decisiones y de instrumentos de decisión de la Unión.

Las autoridades eslovacas ponen en valor el reconocimiento la subjetividad legal de la Unión Europea que hasta ahora tenían solo las tres Comunidades Europeas (Comunidad Europea del Carbón y el Acero, Comunidad Europea Económica, Euratom). La Unión Europea constituida por Maastrich en el año 1992, era sobre todo el sinónimo para el ámbito de la Política común exterior y de seguridad y el ámbito de justicia y de interior y hasta ahora no había asumido la forma jurídica todos los compromisos de las tres comunidades.

Hasta tiempos recientes, no existía en Eslovaquia una posición unánime sobre la ratificación del Tratado Constitucional por la vía referéndum. La cuestión no está decidida, aunque se debe destacar que al igual que en el caso de la República Checa, el referéndum tendría solo un carácter consultivo.

La vía del referéndum está regulada por la Constitución y por y la Ley 564/1992. En Eslovaquia, según el Artículo 93.3 de la Constitución existen los siguientes casos donde se prohíbe convocar el referéndum: derechos humanos y libertades, fiscalidad y el presupuesto de estado.

La Constitución eslovaca, considera al Tratado Constitucional un tratado internacional, sin que por ello, la clase política y la sociedad eslovacas resten valor a la carta magna europea. En Eslovaquia se le da mucha importancia a la transferencia de parcelas de competencias estatales a las instituciones de la Unión Europea.

Teniendo, en cuenta lo anterior, hay que resaltar que en Eslovaquia resuenan algunas voces jurídicas que caracterizan al Tratado como una Constitución al uso, es decir, una verdadera Constitución de la Unión Europea, que daría lugar a un Superestado. Según esta interpretación de dudoso rigor jurídico, el Artículo 2 de la Constitución Eslovaca, impone una aprobación obligatoria por el referéndum.

Otros visiones jurídicas defienden la opinión que el Tratado representa una interferencia importante a las competencias de un Estado, y por ello recomiendan la celebración de un referéndum consultivo. En este caso, el referéndum formalmente es convocado por el Presidente, en base a la resolución del Consejo Nacional de Eslovaquia (el Parlamento) o en base a una petición firmada por más que 350.000 ciudadanos, según el Artículo 95,1 de la Constitución de Eslovaquia. El referéndum debe ser realizado en el plazo de 90 días

48 Se agradece la información y cooperación aportadas por Joanna Grodzka, Consejera de Asuntos Europeos de la Embajada de Polonia en España, y Beata Wojna, miembro del Instituto de Relaciones Internacionales de Polonia. 
tema del referéndum es un tema que se piense en serio, porque en un referéndum tienen dos variantes: pueden poner la cruz en el «sí̀ o poner la cruz en el «no». Yo creo que en este referéndum los ciudadanos de los países europeos, según sus propias convicciones, podrán reaccionar con un sí o con un no. Es decir, ningún tipo de dictado hoy en día está al orden de día, ni una nueva reedición o escribir de nuevo la Constitución Europea.» ${ }^{49}$

Por el momento hay en la República Checa dos posiciones claramente diferenciadas. Por un lado, el gobierno que apoya el Tratado Constitucional, y por otro, la oposición representada por el partido más influyente, el ODS, que ha ganado en Chequia las elecciones al Parlamento Europeo, y que por el momento, lidera en las encuestas en cuanto al apoyo político de la opinión pública.

El cuadro de situación en la República Checa parece tornarse, incluso, más complejo, según las encuestas de opinión pública, parece por ahora, que el electorado del partido gobernante PSD (Partido Social Demócrata), que apoya al Tratado constitucional, se considera menos europeo. En sentido contrario, el electorado del ODS, que rechaza al Tratado consistucional, se considera el más europeo. ${ }^{50}$

Sin embargo, las posturas institucionales de fondo no ponen en riesgo la ratificación del Proyecto de Tratado Constitucional de la Unión Europea, y por tanto, no deben ser confundidas con los cuestionamientos legítimos derivados del debate democrático, o, con la contienda política doméstica que en ocasiones se disputa en el escenario nacional con el tema europeo. No debemos olvidar que en este país la adhesión a la Unión Europea recibió un apoyo del $77,3 \%$ de los ciudadanos que participaron en el referéndum.

El discurso del Jefe de Estado Checo, Václav Kalus, pronunciado en el Senado de España, durante su última visita oficial, indica que los cuestionamientos democráticos al Proyecto de Tratado Constitucional de la Unión son compatibles con un apoyo al mismo.

Václav Kalus: «Hoy en día nuestros dos países pertenecen a democracias asentadas y prósperas, forman parte integra de la Alianza Atlántica y de la Unión Europea, de la cual la República Checa es miembro con plenos derechos desde el pasado mes de mayo. Nos unen valores comunes, nos une el interés por una Europa abierta, dinámica y próspera, nos une el interés por un mundo seguro, pacífico y estable. (...) Sé por mi propia experiencia lo importante que es el papel del Parlamento en la vida de un país democrático — antes de ser elegido Presidente de la República, desempeñé el cargo de Presidente de la Cámara Baja del Parlamento checo. Considero imprescindible implicarnos en nuestro esfuerzo común para encontrar un papel y un peso adecuados de los parlamentos nacionales en los asuntos europeos en vista que son órganos que disponen de una legitimidad democrática real. No debemos permitir que éstos pierdan su influencia e importancia a favor de las estructuras burocráticas de Bruselas no sujetas a elecciones. Considero que la mayor amenaza a la cual debemos enfrentarnos en la Unión Europea, es el déficit democrático y el alejamiento de decisiones de los ciudadanos dentro del margen de la Unión Europea. No existe una nación política europea, por lo cual el papel de los parlamentos nacionales, como avales de un desarrollo democrático, es insustituible». ${ }^{51}$

\subsubsection{Eslovaquia}

Eslovaquia es partidaria de la necesidad vital de una Constitución para la Unión 
socio fundador de la Unión.

Se puede hacer extensible la visión europea del ex-presidente del Gobierno de Hungría, Gyula Horn, a toda la sociedad civil de aquel país y de los nuevos Estados miembros de la Unión: «La Unión Europea de 25 miembros promete cambios reales y palpables. Es de importancia histórica que los nuevos países miembros de la UE sean activos partícipes en la prevención de catástrofes naturales y en la defensa del consumidor. El funcionamiento de las integraciones significa a la vez que están desapareciendo las hostilidades en la región. La transformación de Europa Central y Oriental señala también que la gente está abierta ante el prevalecimiento de las normas europeas. A su juicio, el pasado debe ser superado. El manejo de los problemas fronterizos, de los derechos de las minorías nacionales y de la herencia del pasado común adquiere un carácter cada vez más europeo. Al mismo tiempo, es un hecho que en esta región la conciencia nacional se mide en centímetros cuadrados, pero a ello se contrapone la seguridad brindada por la integración frente a las crisis financieras y económicas externas. Tiene plena aceptación que el ingreso en la Unión Europea facilita la nivelación con los Estados desarrollados, así como el establecimiento de las bases del bienestar y la participación a igual rango en la toma de las decisiones europeas». ${ }^{53}$

El profesor István Szilágyi, Director del Departamento de Ciencias Sociales y de Estudios Europeos de la Universidad de Veszprém, nos brinda algunas claves clarificadoras del devenir de la vida política húngara en relación a la Unión Europea, que merecen ser reproducidos: «El objeto mas prioritario de la nueva democracia húngara era la adhesión a la Unión Europea. Las negociaciones oficiales comenzaron en marzo de 1998 y se terminaron en diciembre de 2002 en Copenhague con la firma de del Acta relativa a las Condiciones de Adhesión y a las Adaptaciones de los Tratados de la Unión Europea y del Tratado de Adhesión. El primer de mayo de 2004 Hungría formalizó su adhesión. La decisión del parlamento húngaro fue que el 12 de abril de 2003 se celebrase el referéndum sobre la adhesión de Hungría a la Unión Europea. En la consulta popular participó el 45,62\% de la población con el derecho de voto.83,76\% de los ciudadanos dio una respuesta afirmativa. La pregunta oficial era: Quiere Usted que Hungría será el miembro de la Unión Europea?. El 16,24\% de los participantes votaron en contra de la adhesión húngara a la Unión Europea. ¿Cómo podemos explicar a este fenómeno? Según las encuestas de los sondeos la inmensa mayoría de los húngaros preguntados apoyaba la entrada del país a la Unión Europea.

Todos los partidos políticos relevantes, excepto El Partido de la Verdad y la Vida Húngara, también apoyaron la adhesión de Hungría a la UE, la mayoría de los ausentes consideró que la cuestión de la ampliación ya estaba resuelta con la firma del Tratado de Adhesión y no tenía ninguna importancia su votación. En cambio aquellos que se opusieron la entrada del país en la Unión Europea participaron en el referéndum, diciendo que toda propaganda oficial sólo trataba de las ventajas de la adhesión, a pesar de que la entrada del país en la UE pone en peligro la soberanía y la independencia de Hungría.

Las elecciones de 13 de junio de 2004 del Parlamento Europeo en Hungría también contribu-

49 Conferencia de Prensa del Presidente de la República Checa, Václav Kalus y del Pesidente del Gobierno de España, José Luis Rodríguez Zapatero. Palacio de la Moncloa, 28 de septiembre de 2004. 
del día de su convocatoria por el presidente.

En el caso de Eslovaquia, el referéndum es válido solo en el caso de que participe un porcentaje superior al $50 \%$ de los ciudadanos y por un resultado que exprese más si la asistencia de la población con el derecho a votar supera 50 por ciento de todo electorado

El referéndum relativo a una misma cuestión se puede repetir solo tres años después de la primera celebración. Por otro lado, se debe destacar que el Artículo 99 de la Constitución de Eslovaquia establece que el resultado de un referéndum puede ser modificado o suspendido por el parlamento por una ley constitucional, solo después de tres años de la fecha de su celebración.

En el supuesto de la celebración de un referéndum sobre Tratado Constitucional de la Unión Europea, el Parlamento eslovaco estaría políticamente vinculado con el resultado, a pesar de que el referéndum tiene solo carácter consultivo. De acuerdo a la actual situación política eslovaca sería difícil imaginarse la votación del Parlamento en un sentido diferente al expresado por el electorado.

Según la Constitución de Eslovaquia los tratados internacionales son ratificados por el Presidente, pero antes deben ser ratificados por el Parlamento. En caso de los tratados internacionales por los que se transmite ejecución de parte de sus derechos a la Comunidad Europea o la Unión Europea deben ser ratificados por mayoría cualificada, es decir más que 3/5 de los 150 diputados. No cabe la duda que el Tratado Constitucional de la UE pertenece a este grupo de los tratados.

Si el Presidente o el gobierno, tienen dudas sobre la conformidad del tratado internacional con la Constitución de Eslovaquia, cabe la alternativa de que antes de presentar el tratado para su ratificación por vía parlamentaria, solicitar la opinión del Tribunal Constitucional. Si el Tribunal decide que el tratado está contra de la Constitución, no recomienda el proceso de su aprobación;

Cabe mencionar que en Eslovaquia, el efecto de una modificación importante de su Constitución, hace la doctrina de monismo donde los importantes compromisos internacionales prevalecen sobre la legislación nacional. Anteriormente la supremacía se relacionaba solo con los tratados internacionales en lo referente a los derechos humanos. Una vez aprobado por el Parlamento, el tratado debe ser publicado o anunciado en la Colección de las leyes de Eslovaquia, así se cumple la condición de validez formal del Tratado. ${ }^{52}$

\subsubsection{Hungría}

La vocación europeísta de Hungría materializada en la reciente ratificación del Tratado de la Constitución, es una prueba palpable de la debilidad y falta de rigor de los análisis dramáticos que se divulgan en la parte occidental de nuestro continente, acerca de los riegos que sufre el proceso de ratificación en el centro y este de Europa, unas dudas euro-céntricas, basadas en una pseuda-legitimidad de origen o complejo de superioridad de

50 Se agradece la información y cooperación aportadas por la Consejera de Asuntos Europeos de la Embajada de la República Checa, Pavla Havrlíková.

51 Klaus, Václvav, Presidente de la República Checa. Discurso en el Senado de España, 27 de septiembre de 2004. 
Lituania: Ratificación parlamentaria, referéndum requerido para tratados que afecten a los aspectos más importantes de la vida de los lituanos (Arts. 135, 1 y 5).

Malta: No existe regulación constitucional, a no ser que se requiera un procedimiento de reforma constitucional.

Ampliación, Convención y Constitución son tres procesos simultáneos de máximo nivel político y jurídico para la Unión Europea. La ampliación dio nacimiento a los Veinticinco y supuso la superación definitiva de la fractura producida en Yalta y el prólogo de futuras adhesiones imprescindibles para el nacimiento de una Única Europa.

A pesar de las complejidades de las trayectorias históricas y de las dinámicas políticas nacionales de los Diez nuevos miembros de la Unión Europea, no hay razones objetivas para pronosticar de modo dramático que las dificultades y obstáculos a superar en el proceso de ratificación vaya a ser más difícil que en el resto de los Estados miembros de la Unión. 
yeron el aumento del déficit democrático de la Unión Europea. Es decir en las elecciones «europeas» participó el 38,5\% de la población con derecho al voto. En la elecciones del Parlamento Europeo vencieron los partidos políticos conservadores. La Alianza de los Jóvenes Demócratas-Alianza Cívico Húngara obtuvo el 47,41\% de los votos así consiguió 12 escaños en el parlamento Europeo. El otro partido conservador, el Foro Democrático Húngaro alcanzó 5,33\% de los votos así recibió un escaño en el Parlamento Europeo. El Partido Socialista Húngaro (el mayor partido del gobierno de coalición social-liberal) obtuvo el 34,31\% de los votos así tiene 9 eurodiputados. La Alianza de Demócratas Libres consiguió 2 escaños $(7,72 \%$ de los votos).En total Hungría tiene 24 eurodiputados.12 de estos (los representantes de la Alianza de los Jóvenes Demócratas-Alianza Cívico Húngara y el Foro Democrático Húngaro ) entraron en el grupo parlamentario del Partido Popular Europeo. Los diputados del Partido Socialista Húngaro forman parte del grupo parlamentario socialista. Los eurodiputados de la Alianza de los Demócratas Libres pertenecen al grupo liberal del Parlamento Europeo.. ${ }^{54}$

El Parlamento de Hungría ratificó el Tratado de Constitución Europea, el 20 de diciembre a las 16.00 horas, siendo así Hungría el segundo país de la Unión, tras Lituania en ratificar el Tratado Constitucional. La votación tuvo los siguientes resultados: 323 votos a favor, 12 votos en contra, 8 abstenciones. Se debe destacar que 42 diputados estuvieron ausentes. Según la participación de los miembros de los diferentes grupos parlamentarios, las orientaciones de los votos y las ausencias fueron los siguientes:

Socialistas húngaros (MSZP): 172 votos a favor, y hubo 6 diputados ausentes.

Partido Popular húngaro (FIDES): 128 votos a favor, 7 votos en contra, 1 abstención y 25 diputados ausentes.

Partido de los Demócratas Libres (SZDSZ): 20 votos a favor.

Partido del Foro Democrático (MDF): 5 abstenciones, 3 diputados ausentes.

Independientes: 3 votos a favor, 5 votos en contra, 2 abstenciones y 8 diputados ausentes..$^{55}$

\subsection{5.- Chipre, Eslovenia, Estonia, Letonia, Lituania y Malta}

Lituania fue el primer país en ratificar el Proyecto de Tratado de Constitución para la Unión Europea por vía parlamentaria el pasado mes de noviembre.

A continuación ofreceré de modo telegráfico algunos datos sobre el proceso de ratificación en los países arriba citados

En caso de que la ratificación se realice por la vía Parlamentaria: ${ }^{56}$

Chipre: Adopción de la vía parlamentaria por el Consejo de Ministros y aprobación por la Cámara de representantes (Art.169).

Eslovenia: Mayoría parlamentaria de 3/5. (Arts. 3 y 8).

Estonia: Mayoría y procedimiento establecidos por ley ( Arts. 120 y 121)

Letonia: Ratificación parlamentaria. La mitad de los parlamentariaos pueden solicitar la celebración de un referéndum (Art. 68).

52 Se agradece la información y cooperación aportadas por Luba Hromková, Consejera de Asuntos Europeos de la Embajada de Eslovaquia. 
53 Horn, Gyula.Ex-presidente del gobierno de Hungría.Doctor en CC. Económicas. Transformación a la húngara. La Musa n 5 (2004-2005): Quince desde desde la caída del Muro de Berlín: Balance y Perspectivas. Facultad de Humanidades de la UCLM. Co-dirección, José Luis González Esteban y Concha Sánz. Subdirección: Rubén Darío Torres Kumbrian ISSN 1759 2803. mmm.uclm.es/lamusa 
54 Prof. Dr. Szilágyi István, Director del Departamento de Ciencias Sociales y de Estudios Europeos de la Universidad de Veszprém, .Hungría: quince años después de la caída del muro de Berlín. La Musa no 5 (20042005): Quince desde desde la caída del Muro de Berlín: Balance y Perspectivas. Facultad de Humanidades de la UCLM. Co-dirección, José Luis González Esteban y Concha Sánz. Subdirección: Rubén Darío Torres Kumbrian ISSN 1759 2803. www.uclm.es/lamusa

55 Se agradece la información y cooperación proporcionadas por Angela Klimes de Gosztonyi, Ministerio de Asuntos Exteriores de Hungría y de Judit Stádler, Consejera de Cultura y Prensa de la Embajada de Hungría. 
56 Closa Montero, Carlos, Área de C. Política y de la Administración, Facultad de Derecho, Universidad de Zaragoza. ARI No 120/ 7/72004- Análisis. La ratificación de la Constitución de la UE: Un campo de minas. Real Instituto Elcano de Estudios Internacionales y Estratégicos. 